\title{
A case-based discussion of clinical problems in the management of patients treated with ruxolitinib for myelofibrosis
}

P. Joy Ho1,2 (corresponding author)

Ashish Bajel ${ }^{3}$

Kate Burbury ${ }^{4}$

Lindsay Dunlop 5,6

Simon Durrant ${ }^{7}$

Cecily Forsyth8

Andrew C. Perkins 9,10

David M. Ross'11

\section{Acknowledgements}

We thank Dr Belinda Butcher CMPP from WriteSource Medical Pty Ltd who provided medical writing services that were funded by an unrestricted educational grant from Novartis.

\section{Conflict of interest disclosure}

P. J. Ho is a member of an advisory board for Novartis and received a research grant to her institution from Novartis.

D. M. Ross has received research funding and honoraria from Novartis.

A.C. Perkins has received honoraria from Novartis.

A. Bajel has received honoraria from Novartis.

S. Durrant has received research funding and has sat on advisory boards for Novartis.

L. Dunlop has received honoraria from Novartis.

C. Forsyth is a member of an advisory board for Novartis, and has received honorarium and a research grant from Novartis.

Corresponding author email: Joy.Ho@sswahs.nsw.gov.au

\section{Word Count [abstract] 180}

\section{Word Count [main text] 3639 (excluding references)}

\footnotetext{
Royal Prince Alfred Hospital, NSW

2 University of Sydney, NSW

3 The Royal Melbourne Hospital, Victoria

4 Peter MacCallum Cancer Centre, Victoria

5 Liverpool Hospital, NSW

6 Western Sydney University, NSW

7 Royal Brisbane Hospitals, Queensland

8 Jarrett Street Specialist Centre, North Gosford, NSW

9 Princess Alexandra Hospital, Queensland

10 Wesley Hospital, Queensland

"SA Pathology, Royal Adelaide Hospital and Flinders Medical Centre, South Australia
}

This is the author manuscript accepted for publication and has undergone full peer review but has not been through the copyediting, typesetting, pagination and proofreading process, which may lead to differences between this version and the Version of Record. Please cite this article as doi: 10.1111/imj.13341 
Formatted for Internal Medicine Journal http://onlinelibrary.wiley.com/journal/10.1111/(ISSN) 1445-5994/homepage/ForAuthors.html Version 12 FINAL1 $1^{\text {th }}$ November 2016 UK Spelling

\section{INTRODUCTION}

Ruxolitinib is a dual JAK1/ JAK2 inhibitor used to treat splenomegaly and/or symptoms associated with myelofibrosis (MF). In higher risk MF patients (International Prognostic Scoring System [IPSS] intermediate-2 or high risk) these responses are accompanied by an improvement in overall survival. ${ }^{1-4}$ In the 5-year follow-up of the COMFORT-2 study the median survival of patients randomised to ruxolitinib was approximately one year greater than in those patients randomised to BAT. Since most of the BAT patients crossed over to ruxolitinib the intention-to-treat analysis likely under-estimates the survival advantage. We previously proposed clinical guidance on the use of ruxolitinib for MF. ${ }^{5}$ The aim of this paper is to draw attention to some practical aspects of ruxolitinib use in the clinic, including a range of common and uncommon clinical scenarios drawn from the authors' experience. Using a case-based approach we discuss the management of patients at risk of bleeding (including thrombocytopenia or anti-thrombotic therapy), patients with MF-related anaemia, the risk of opportunistic infection, pulmonary hypertension, ruxolitinib treatment as a bridge to transplantation, and the treatment of patients with lower risk MF.

\section{MANAGEMENT OF CYTOPENIA}

\section{Thrombocytopenia}

\section{Case 1}

A 67-year-old man was referred with progressive constitutional symptoms and massive splenomegaly due to JAK2-positive primary MF. Seven years earlier he had been diagnosed with a myeloproliferative neoplasm after presenting with recurrent venous thromboembolism (deep vein thrombosis and pulmonary embolism). He was anticoagulated with warfarin (target international normalised ratio (INR) of 2.5). He had previously received hydroxycarbamide (HC, previously known as hydroxyurea) without significant symptomatic improvement. Investigations revealed haemoglobin $145 \mathrm{~g} / \mathrm{L}$, 
white cell count $15.3 \times 10^{9} / \mathrm{L}$ and platelets of $334 \times 10^{9} / \mathrm{L}$. His renal and hepatic function tests were normal.

He was commenced on ruxolitinib $20 \mathrm{mg}$ twice daily after careful consideration of his increased risk of bleeding. Weekly monitoring of INR and blood counts was initiated. After three weeks of ruxolitinib treatment, his platelet count had fallen to $100 \times 10^{9} / \mathrm{L}$, and his warfarin dose had been reduced due to an INR above the target range at 4.2. He experienced significant improvement in his constitutional symptoms and a reduction in the size of his palpable spleen from $25 \mathrm{~cm}$ to $17 \mathrm{~cm}$ below the costal margin. His platelet count continued to fall and after five weeks of ruxolitinib therapy his platelet count was $76 \times 10^{9} / \mathrm{L}$, and hence his ruxolitinib dose was reduced to $15 \mathrm{mg}$ twice daily. Over the ensuing months his platelet count fell further, leading to further ruxolitinib dose reductions, but as the dose was reduced his symptoms started to return, and he was extremely reluctant to remain on a lower ruxolitinib dose. Given that his INR was stable in the therapeutic range, and he had no evidence of bleeding, he remained on ruxolitinib 15 $\mathrm{mg}$ twice daily. His platelet count is in the range of $50-100 \times 10^{9} / \mathrm{L}$. During 18 months of ruxolitinib treatment he had experienced no bleeding events.

Thrombosis is a well-recognized complication of myeloproliferative neoplasms and the risk of recurrent thrombosis is high. It is therefore not uncommon to encounter patients with myelofibrosis on anticoagulant therapy. The risk of bleeding in myelofibrosis can be increased for many reasons, including thrombocytopenia, abnormal platelet function, portal hypertension, synthetic liver dysfunction, and potentially exacerbated by anti-thrombotic treatment.6,7 Bleeding complications were more common in the ruxolitinib-treated patients in both COMFORT-I (versus placebo) and COMFORT-II (versus best available therapy). 1, 2, 8, 9 In 
Formatted for Internal Medicine Journal http://onlinelibrary.wiley.com/journal/10.1111/(ISSN) 1445-5994/homepage/ForAuthors.html Version 12 FINAL1 $1^{\text {th }}$ November 2016 UK Spelling

COMFORT-II, less than $2 \%$ of patients experienced serious bleeding events and the exposureadjusted event rate of haematoma was 26 per 100 patient-years, and of epistaxis was 24 per 100 patient-years. ${ }^{4}$ Treatment-emergent thrombocytopenia is likely a major contributor to the increased bleeding events, but JAK2 inhibitors might also affect platelet function, since the JAK-STAT pathway is involved in platelet activation. ${ }^{10}$ Beyond the first two years the rate of bleeding tends to reduce, possibly reflecting dose reductions and a lower rate of thrombocytopenia. ${ }^{2}$ The risk of bleeding secondary to portal hypertension might be reduced by ruxolitinib, which has been reported to lower portal venous pressure, presumably due to the reduction in splenomegaly and extramedullary haematopoiesis in the liver. ${ }^{11}$

Thrombocytopenia is the dose-limiting toxicity of ruxolitinib, but in some patients with significant thrombocytopenia prior to commencing ruxolitinib paradoxical increases in platelet count are observed. Grunwald and colleagues suggested possible mechanisms for increased platelet counts, which may include decreased splenic sequestration through reduction in splenomegaly or improvement in the haematopoietic microenvironment through decreased inflammatory cytokine production. ${ }^{12}$

The COMFORT studies were not powered to assess the risk of thrombotic events, but a metaanalysis combining results from these studies of myelofibrosis and from the RESPONSE study (ruxolitinib vs best available treatment for HC-resistant or -intolerant polycythaemia vera) showed a reduction in the rate of venous thrombosis with ruxolitinib. ${ }^{13}$ Nevertheless, in a patient with recurrent venous thrombosis there is no evidence available to indicate that long-term anticoagulation can be safely withdrawn.

\section{Practice points [Thrombocytopenia/Anticoagulation]:}

1. Ruxolitinib may contribute to the increased risk of bleeding, but this risk should be balanced against clinical benefit in symptom control and splenomegaly.

2. Ruxolitinib can be used safely in thrombocytopenic patients with appropriate dose 
titration and monitoring of blood counts.

\section{Anaemia}

Case 2

A 57-year-old female was diagnosed with triple-negative (JAK-/CALR-/MPL-) essential thrombocythaemia (ET). She had no other medical comorbidities. Two years later her marrow confirmed evolution to post-ET MF with DIPSS risk intermediate-1. She was commenced on HC (duration 6 months), but treatment was complicated by the development of symptomatic anaemia (haemoglobin $102 \mathrm{~g} / \mathrm{L}$ ) and she developed progressive and tender splenomegaly (3cm below the lower costal margin) and constitutional symptoms. She commenced ruxolitinib $20 \mathrm{mg}$ twice daily and although over the first two to three months of ruxolitinib treatment she experienced a reduction in her initial symptoms, there was progressive symptomatic anaemia (Table 1).

\begin{tabular}{|l|c|c|c|}
\hline & Haemoglobin $(\mathrm{g} / \mathrm{L})$ & $\begin{array}{c}\text { White Cell Count }(\mathrm{x} \\
\left.10^{9} / \mathrm{L}\right)\end{array}$ & Platelets (x 109/L) \\
\hline Baseline & 102 & 35 & 424 \\
\hline Month 1 & 99 & 29 & 268 \\
\hline Month 3 & 91 & 21 & 137 \\
\hline Month 6 & 88 & 24 & 138 \\
\hline
\end{tabular}

\section{Table 1: Blood count over a six month period for case 2}

Dose reduction of ruxolitinib to $15 \mathrm{mg}$ twice daily stabilised her blood parameters with sustained improvement in her symptoms and reduction in spleen size.

She remains on ruxolitinib $15 \mathrm{mg}$ twice daily, with an overall improvement in performance status, symptoms, and proliferative features (splenomegaly, white cell count, and platelet count), and has been HLA-typed with a view to subsequent allogeneic stem cell 
transplantation.

Almost half of the patients treated in the COMFORT studies experienced anaemia of $100 \mathrm{~g} / \mathrm{L}$ or worse prior to treatment with ruxolitinib. Following treatment with ruxolitinib, anaemia is dose-dependent, ${ }^{14}$ and typically worsens over the first two to three months, reaching a nadir of 15 to $20 \mathrm{~g} / \mathrm{L}$ below baseline levels, but recovering to approximately $10 \mathrm{~g} / \mathrm{L}$ below baseline levels, probably reflecting dose reductions. ${ }^{15}$ Complete blood counts should be monitored more frequently in the early months of treatment and other causes of anaemia (e.g. blood loss) should be considered as well as dose adjustment of ruxolitinib. ${ }^{5}$

In the COMFORT studies anaemia was primarily managed with packed red blood cell transfusions. Erythropoiesis-stimulating agents (ESAs), another option for managing MFrelated anaemia, were used in a small number of patients treated with ruxolitinib in the COMFORT study ( $n=13 / 146) .{ }^{16}$ In those patients concomitant use of ESAs and ruxolitinib did not appear to affect the efficacy of ruxolitinib, 16 although larger studies are needed to confirm this. ESAs are not registered for use in Australia for MF-related anaemia. MF patients with lower endogenous erythropoietin levels (<125 U/L) and requiring fewer than 2 units of red cell transfusions per month are more likely to respond to ESAs. ${ }^{17}$

\section{Practice points [Anaemia]:}

1. Exclude additional factors that may be contributing to anaemia.

2. Support haemoglobin with transfusions, as required. ESAs do not appear to affect the efficacy of ruxolitinib, and may be useful in selected patients. ESAs are not approved in Australia for MF-related anaemia.

3. Anaemia on ruxolitinib is dose-dependent and may respond to dose reduction.

\section{INFECTION}

This article is protected by copyright. All rights reserved. 


\section{Case 3}

A 62 year-old woman, without additional comorbidities, was diagnosed with post-ET myelofibrosis, with rapidly progressing anaemia, resulting in a high transfusion requirement ( 3 units of packed red cells every 3 weeks), painful splenomegaly, and constitutional symptoms. She commenced ruxolitinib $20 \mathrm{mg}$ twice daily, with good symptomatic response but no change in her transfusion requirement and transfusion-related iron overload with a serum ferritin level of up to $1,500 \mu \mathrm{g} / \mathrm{L}$.

Approximately 27 months after commencing ruxolitinib she was admitted with delirium and altered personality. A lumbar puncture revealed Cryptococcal meningitis. Ruxolitinib was interrupted and she was treated with high dose amphotericin and fluconazole and subsequent lifelong prophylactic fluconazole 400 mg daily. Her mental state gradually returned to normal over the next two to three months. During the period when ruxolitinib was stopped there was a gradual return of her constitutional symptoms and painful splenomegaly. She was recommenced on ruxolitinib 8 weeks after detection of the infection, at a reduced dose of $15 \mathrm{mg}$ twice daily.

\section{Case 4}

A 60-year-old man presented with weight loss, bone pain, early satiety with splenomegaly palpable $13 \mathrm{~cm}$ below the costal margin. The haemoglobin was $145 \mathrm{~g} / \mathrm{L}$, white cell count $22.7 \times 10^{9} / \mathrm{L}$, and platelets $309 \times 10^{9} / \mathrm{L}$ with a leukoerythroblastic film. A bone marrow biopsy was consistent with primary MF (IPSS Intermediate-1). He commenced ruxolitinib and had symptomatic improvement accompanied by a reduction in spleen size (to nonpalpable). After 4 months he developed fever, cough, and shortness of breath. Pleural aspirate and sputum samples grew Mycobacterium tuberculosis. He was treated with ethambutol, pyrazinamide, rifampicin, and isoniazid. Ruxolitinib was ceased, but reintroduction will be considered once the tuberculosis is controlled. 
Formatted for Internal Medicine Journal http://onlinelibrary.wiley.com/journal/10.1111/(ISSN) 1445-5994/homepage/ForAuthors.html Version 12 FINAL1 $1^{\text {th }}$ November 2016 UK Spelling

Ruxolitinib modulates dendritic cell function resulting in impaired CD4+ and CD8+ T-cell priming, and delayed vaccine-induced hepatic adenoviral clearance. 18,19 These changes, along with alterations in cytokine production, appear to be associated with reactivation of viral infections (varicella, hepatitis B, cytomegalovirus), and other atypical infections (tuberculosis, Pneumocystis, Cryptococcus). ${ }^{18}$ In the COMFORT-I study a slightly increased risk of herpes zoster was observed in patients prescribed ruxolitinib (between 3.5 and 5.0 cases per 100 patient years of exposures, compared to 1.0 with placebo)..$^{3}$ Iron overload is also reported to be a risk factor for many infections, including Cryptococcus, 20 and may have been a contributing factor in this patient.

Case 3 also presents a delayed return of symptoms following ruxolitinib cessation. Following interruption of ruxolitinib treatment symptoms usually return to the pre-treatment level within a week. In rare instances a severe withdrawal syndrome with acute haemodynamic instability has been reported."1 This is thought to be related to cytokine rebound, and some clinicians use a tapered dose reduction or prophylactic prednisolone treatment. ${ }^{21}$

\section{Practice points}

1. Patients should be screened for latent infections that may reactivate during ruxolitinib treatment, and for which prophylactic treatment would be recommended (e.g. hepatitis B; tuberculosis in at-risk patients)

2. Patients should be warned of the risk of opportunistic infection, including reactivation of herpes zoster, and educated to present early in case of symptoms.

3. Consider secondary prophylaxis (e.g. famciclovir) following an episode of herpes zoster. Primary prophylaxis is not recommended.

\section{LOWER RISK DISEASE}

This article is protected by copyright. All rights reserved. 
Formatted for Internal Medicine Journal http://onlinelibrary.wiley.com/journal/10.1111/(ISSN) 1445-5994/homepage/ForAuthors.html Version 12 FINAL1 $1^{\text {th }}$ November 2016 UK Spelling

Case 2 featured a patient treated for symptomatic MF in the intermediate-1 risk group (IPSS). The COMFORT studies included only patients with IPSS intermediate-2 or high-risk MF, but data from non-randomised studies confirm that both symptomatic and splenic responses are also seen in patients with intermediate- 1 disease. ${ }^{22}$ In the JUMP study $61 \%$ of patients with intermediate-1 disease achieved a $50 \%$ or greater reduction in palpable spleen length at week 48 , and $30 \%$ had symptom improvement. ${ }^{23}$ In the ROBUST study there were fourteen patients with intermediate-1 disease. ${ }^{24}$ At week $48,57.1 \%$ of these patients had a $50 \%$ or greater reduction in spleen length or a $50 \%$ or greater reduction in total symptom score using the MF-Symptom Assessment Form, a proportion similar to that reported in intermediate-2 or high-risk patients. ${ }^{24}$

There is a survival benefit for ruxolitinib in advanced MF but significant molecular responses are rare. The overwhelming majority of MF patients treated with ruxolitinib have had constitutional symptoms or symptomatic splenomegaly. It is unknown whether treatment earlier in the course of disease might alter the natural history of MF. The RETHINK trial (NCT02598297) is currently enrolling lower risk MF patients (based on clinical risk score) who have high risk molecular mutations (ASXL1, EZH2, IDH1/2, SRSF2) to test whether early treatment offers any benefit in patients who would not ordinarily be considered for ruxolitinib treatment.

\section{Practice points}

1. Ruxolitinib treatment provides clinical benefit in intermediate-1 risk patients with symptomatic splenomegaly or other MF-related symptoms. However, there has been no randomised study of ruxolitinib in intermediate-1 or low risk patients, and it is unknown whether treatment will provide a survival benefit in these patients.

2. In lower risk patients the potential benefits of ruxolitinib therapy must be weighed against the increased risk of infection and cytopenia. 


\section{BRIDGE TO TRANSPLANTATION}

\section{Case 4}

A 57-year-old man with a 17-year history of primary MF had been treated with $\mathrm{HC}$ for more than twelve years to control his thrombocytosis and reduce his splenomegaly. The dose of HC had been titrated according to tolerance and response until he developed progressive splenomegaly and cytopenia, a decline in performance status, and increased constitutional symptoms.

He was commenced on ruxolitinib $20 \mathrm{mg}$ twice daily. He was found to have an HLAmatched sibling, and he agreed to allogeneic stem cell transplantation. He continued on ruxolitinib prior to transplantation with the aim of improving his performance status and reducing his splenomegaly. He ceased ruxolitinib on the day before commencing transplant conditioning, and experienced no withdrawal symptoms.

Case series reporting patients treated with ruxolitinib prior to transplant have suggested that some of the negative predictors for outcome post-allograft can be partially overcome (e.g. massive splenomegaly). ${ }^{25}$ A study reporting allograft outcomes in patients treated with JAK inhibitors (predominantly ruxolitinib) showed that the quality of response to JAK inhibitor treatment influenced overall survival. ${ }^{26}$ The overall survival of patients transplanted while responding was significantly better than that of patients transplanted at disease progression. ${ }^{26}$ JAK inhibitor treatment should not be considered as a long-term alternative to transplantation in younger MF patients with a suitable donor.

It is thought that down-regulation of cytokines may have a beneficial effect on graft failure and graft-versus-host disease. ${ }^{25}$ Ruxolitinib has been explored as a treatment for corticosteroid-refractory graft-versus-host disease in both the acute and chronic setting after allogeneic stem cell transplantation. ${ }^{27}$ In contrast, tumour lysis syndrome and cardiogenic 
Formatted for Internal Medicine Journal http://onlinelibrary.wiley.com/journal/10.1111/(ISSN) 1445-5994/homepage/ForAuthors.html Version 12 FINAL1 $1^{\text {th }}$ November 2016 UK Spelling

shock have been reported in patients treated with ruxolitinib prior to transplantation. 28 This may have been due to the timing of ruxolitinib withdrawal, since others have not reported any rebound phenomenon. ${ }^{29}$ The optimal timing of ruxolitinib withdrawal in the pre-transplant period remains unclear, but there is a trend to continue treatment until immediately prior to conditioning or even until the end of conditioning. ${ }^{11,21}$ Ruxolitinib prior to transplantation in MF patients is the subject of an ongoing Phase 2 clinical trial (NCT01790295).

\section{Practice points}

1. The use of ruxolitinib prior to stem cell transplantation has been reported to be beneficial in case series, but continues to be investigated in clinical trials.

2. The optimal timing of ruxolitinib discontinuation pre-transplant is unknown, but expert opinion favours continuing at least until the start of conditioning.

3. Ruxolitinib should not replace transplantation in younger, transplant-eligible patients

\section{PULMONARY HYPERTENSION}

\section{Case 5}

A 42-year-old woman with a history of diabetes, hypothyroidism, hypertension and coronary arterial disease presented with splenomegaly. Her haemoglobin was $106 \mathrm{~g} / \mathrm{L}$, white cell count $8.1 \times 10^{9} / \mathrm{L}$, and platelets $564 \times 10^{9} / \mathrm{L}$. She had the JAK2 V617F mutation. A bone marrow biopsy established the diagnosis of primary MF, IPSS low risk.

Two years after the initial diagnosis she experienced a six-month period of progressive oedema, initially in the lower limbs, but progressing to involve the breasts and upper limbs. She gained 20 kilograms in weight and developed extreme fatigue and lethargy, drenching sweats, exertional dyspnoea, and a persistent cough. Her haemoglobin was $103 \mathrm{~g} / \mathrm{L}$, white cell count $14.2 \times 10^{9} / \mathrm{L}$ and platelets $1,034 \times 10^{9} / \mathrm{L}$. Blasts were $<1 \%$ in the 
peripheral blood. Her renal function was normal, but she developed hyperuricaemia, cholestatic liver function test abnormalities, and a markedly increased brain natriuretic peptide level of $3131 \mathrm{ng} / \mathrm{L}$ (normal range $<450 \mathrm{ng} / \mathrm{L}$ ). Echocardiography revealed a dilated and impaired right ventricle, and severe pulmonary hypertension with indirect (non-invasive echocardiography) measurement of pulmonary artery systolic pressure at 76 $\mathrm{mm} \mathrm{Hg}$. She had no evidence of pulmonary embolism on CT pulmonary angiography nor pulmonary myeloid metaplasia on Tc-99m sulphur colloid scintigraphy. She was diagnosed with pulmonary hypertension and right heart failure. Her DIPSS risk category was now intermediate-1 (due to constitutional symptoms). She commenced aggressive diuretic therapy, allopurinol, $\mathrm{HC}$, and aspirin.

Her platelet count improved rapidly on $\mathrm{HC}$, but after two months she had a haemoglobin less than $100 \mathrm{~g} / \mathrm{L}$ and persistent constitutional symptoms. HC was stopped and she started ruxolitinib $20 \mathrm{mg}$ twice daily. Three months following introduction of ruxolitinib she was requiring occasional blood transfusions for haemoglobin levels below $80 \mathrm{~g} / \mathrm{L}$ and her platelet count was stable in the range $200-400 \times 10 \% / \mathrm{L}$. She had lost $20 \mathrm{~kg}$ and had marked symptomatic improvement in dyspnoea, cough, and fatigue. Her pulmonary artery systolic pressure had fallen to $36 \mathrm{~mm} \mathrm{Hg}$ and she had a normal right ventricle size and function.

In the following year she received therapy to improve her comorbidities including insertion of cardiac stents, and the control of diabetes, weight, and lipids. She has a matched unrelated donor and will proceed to an allogeneic stem cell transplant. Ruxolitinib will be ceased at commencement of conditioning.

Pulmonary hypertension is an important complication of MF that is under-recognised. One study reported that just over one third of MF patients developed pulmonary hypertension. 30 The development of pulmonary hypertension in MF may be linked to abnormal angiogenesis, 
Formatted for Internal Medicine Journal http://onlinelibrary.wiley.com/journal/10.1111/(ISSN) 1445-5994/homepage/ForAuthors.html Version 12 FINAL1 $1^{\text {th }}$ November 2016 UK Spelling

endothelial dysfunction and/or pulmonary myeloid metaplasia. Increased pressures are also thought to result from chronic anaemia. 30 Since myelofibrosis patients have an increased risk of venous thromboembolism, ${ }^{7}$ it is also important to assess patients for chronic thromboembolic disease.

Ruxolitinib has been reported to improve pulmonary artery pressure and right ventricle function in up to two-thirds of MF patients with pulmonary hypertension, ${ }^{31}$ and can reduce plasma levels of brain natriuretic peptide, von Willebrand factor and uric acid, and increase nitric oxide levels. 30 It is possible that ruxolitinib may reverse pulmonary hypertension through nitric oxide and cytokine modulation. ${ }^{30}$ However, there has also been a case report of worsening of pulmonary hypertension in a patient treated with ruxolitinib. ${ }^{32}$

\section{Practice points}

1. Pulmonary hypertension is a serious complication of MF that is under-recognised.

2. Pulmonary hypertension in MF is multifactorial and potential contributing factors should be assessed carefully to guide optimal treatment.

3. In case reports ruxolitinib has been reported to improve pulmonary artery pressures and right ventricular function in a proportion of patients.

\section{TRANSFORMATION TO ACUTE MYELOID LEUKAEMIA}

\section{Case 7}

A 61-year-old man presented with weight loss, a leukoerythroblastic blood film, and splenomegaly. The haemoglobin and platelet counts were normal. A bone marrow biopsy showed primary MF with partial trisomy 9. In addition to JAK2 V617F there was a high risk mutation in EZH2. The patient was enrolled into the PERSIST-1 trial of pacritinib (400 mg od), but there was minimal clinical response so the patient was switched to ruxolitinib $15 \mathrm{mg}$ bd after 9 months. There was an initial response with significant reduction in splenomegaly 
and improvement of symptoms, but after three months the disease progressed to acute myeloid leukaemia (AML). There was a good clinical response to induction therapy with cytosine arabinoside and idarubicin ('7+3') and a reduced intensity sibling allograft was performed in first remission. Unfortunately, AML recurred post-allograft and the patient died at day 105 post-transplant.

Transformation to acute myeloid leukaemia occurs in $8 \%$ to $23 \%$ of patients with MF in the first ten years after diagnosis. A number of risk factors for AML transformation have been identified, including white blood cell count less than $3 \times 10 \% / L$, thrombocytopenia, blasts of $5 \%$ or more in the peripheral blood or bone marrow, unfavourable karyotype, and high risk molecular mutations. ${ }^{33}$ Such patients might benefit from more aggressive therapeutic approaches, including investigational approaches and early stem cell transplantation. ${ }^{33}$ In the COMFORT studies the rate of progression to AML was almost identical in the ruxolitinib and comparator arms (placebo or best available therapy), indicating that ruxolitinib has no impact on the risk of AML progression. 2,8 Ruxolitinib has modest efficacy as a single agent in post-MF AML, with reduced blast counts in a minority of patients. Ruxolitinib has been combined with hypomethylating chemotherapy in post-MF AML, and is currently undergoing phase 2 studies in combination with decitabine for patients with AML (NCT02257138). The outcome of transformed MF patients remains poor. Allogeneic transplantation is reported to result in overall survival of approximately $20 \%$ at 3 years. Post-MF AML remains an area of unmet need.

\section{Practice points}

1. Consider early allogeneic stem cell transplantation in high risk MF patients (prior to transformation)

2. In a patient with post-MF AML allogeneic stem cell transplantation is recommended in eligible patients who achieve some degree of disease control in 
response to induction chemotherapy, hypomethylating agents, or investigational treatment.

\section{CONCLUSION}

Ruxolitinib has become an accepted treatment for MF patients with symptomatic disease of intermediate-1 or higher risk. The optimal use of ruxolitinib requires clinicians to be aware of the toxicities and complications of treatment. Dose-dependent toxicities such as anaemia and thrombocytopenia must be balanced against the dose-dependent responses in symptoms and spleen size. Allogeneic stem cell transplantation remains the only curative treatment for MF, and younger transplant-eligible patients should still be considered for this therapy. The transplant-related mortality is traditionally quite high, so the decision to transplant is difficult. Preliminary experience indicates that pre-transplant ruxolitinib treatment might improve transplant outcomes. Transplantation should not be deferred until disease progression, since response status at the time of transplantation is associated with posttransplant survival.

\section{REFERENCES}

1 Cervantes F, Vannucchi AM, Kiladjian J-J, Al-Ali HK, Sirulnik A, Stalbovskaya V, et al. Three-year efficacy, safety, and survival findings from COMFORT-II, a phase 3 study comparing ruxolitinib with best available therapy for myelofibrosis. Blood. 2013; 122: 4047-53.

2 Verstovsek S, Mesa RA, Gotlib J, Levy RS, Gupta V, DiPersio JF, et al. Efficacy, safety, and survival with ruxolitinib in patients with myelofibrosis: results of a median 3-year follow-up of COMFORT-I. Haematologica. 2015; 100: 479-88.

3 Verstovsek S, Mesa RA, Gotlib JR, Gupta V, DiPersio JF, Catalano JV, et al. Long-term outcomes of ruxolitinib (rux) therapy in patients (pts) with myelofibrosis (mf): 5-year final 
Formatted for Internal Medicine Journal http://onlinelibrary.wiley.com/journal/10.1111/(ISSN) 1445-5994/homepage/ForAuthors.html Version 12 FINAL1 $1^{\text {th }}$ November 2016 UK Spelling

efficacy and safety analysis from COMFORT-I. European Haematology Association.

Copenhagen 2016

$4 \quad$ Harrison CN, Vannucchi AM, Kiladjian JJ, Al-Ali HK, Gisslinger H, Knoops L, et al. Longterm findings from COMFORT-II, a phase 3 study of ruxolitinib vs best available therapy for myelofibrosis. Leukemia. 2016; 30: 1701-7.

5 Ho PJ, Marlton P, Tam C, Stevenson W, Ritchie D, Bird R, et al. Practical management of myelofibrosis with ruxolitinib. Intern Med J. 2015; 45: 1221-30.

6 Finazzi G, Carobbio A, Thiele J, Passamonti F, Rumi E, Ruggeri M, et al. Incidence and risk factors for bleeding in 1104 patients with essential thrombocythemia or prefibrotic myelofibrosis diagnosed according to the 2008 WHO criteria. Leukemia. 2012; 26: 716-9.

7 Barbui T, Carobbio A, Cervantes F, Vannucchi AM, Guglielmelli P, Antonioli E, et al. Thrombosis in primary myelofibrosis: incidence and risk factors. Blood. 2010; 115: 778-82.

8 Verstovsek S, Mesa RA, Gotlib J, Levy RS, Gupta V, DiPersio JF, et al. A double-blind, placebo-controlled trial of ruxolitinib for myelofibrosis. N Engl J Med. 2012; 366: 799-807.

9 Harrison C, Kiladjian J-J, Al-Ali HK, Gisslinger H, Waltzman R, Stalbovskaya V, et al. JAK inhibition with ruxolitinib versus best available therapy for myelofibrosis. New England Journal of Medicine. 2012; 366: 787-98.

10 Lu WJ, Lin KC, Huang SY, Thomas PA, WU YH, Wu HC, et al. Role of a Janus kinase 2dependent signaling pathway in platelet activation. Thromb Res. 2014; 133: 1088-96.

11 Mascarenhas J, Hoffman R. A comprehensive review and analysis of the effect of ruxolitinib therapy on the survival of patients with myelofibrosis. Blood. 2013; 121: 4832-7. 
Formatted for Internal Medicine Journal http://onlinelibrary.wiley.com/journal/10.1111/(ISSN) 1445-5994/homepage/ForAuthors.html Version 12 FINAL1 $1^{\text {th }}$ November 2016 UK Spelling

12 Grunwald MR, Spivak JL. Ruxolitinib Enhances Platelet Production in Patients With Thrombocytopenic Myelofibrosis. J Clin Oncol. 2016; 34: e38-40.

13 Samuelson BT, Vesely SK, Chai-Adisaksopha C, Scott BL, Crowther M, Garcia D. The impact of ruxolitinib on thrombosis in patients with polycythemia vera and myelofibrosis: a meta-analysis. Blood Coagul Fibrinolysis. 2016; 27: 648-52.

14 Mesa RA, Cortes J. Optimizing management of ruxolitinib in patients with myelofibrosis: the need for individualized dosing. J Hematol Oncol. 2013; 6: 79.

15 Novartis Pharmaceuticals Australia Pty Ltd. Jakavi® (ruxolitinib) product information. 2015.

16 McMullin MF, Harrison CN, Niederwieser D, Demuynck H, Jakel N, Gopalakrishna P, et al. The use of erythropoiesis-stimulating agents with ruxolitinib in patients with myelofibrosis in COMFORT-II: an open-label, phase 3 study assessing efficacy and safety of ruxolitinib versus best available therapy in the treatment of myelofibrosis. Exp Hematol Oncol. 2015; 4: 26.

17 Cervantes F, Alvarez-Larran A, Hernandez-Boluda JC, Sureda A, Torrebadell M, Montserrat E. Erythropoietin treatment of the anaemia of myelofibrosis with myeloid metaplasia: results in 20 patients and review of the literature. Br J Haematol. 2004; 127: 399403.

18 Heine A, Brossart P, Wolf D. Ruxolitinib is a potent immunosuppressive compound: is it time for anti-infective prophylaxis? Blood. 2013; 122: 3843-4.

19 Heine A, Held SA, Daecke SN, Wallner S, Yajnanarayana SP, Kurts C, et al. The JAKinhibitor ruxolitinib impairs dendritic cell function in vitro and in vivo. Blood. 2013; 122: 1192202.

This article is protected by copyright. All rights reserved. 
Formatted for Internal Medicine Journal http://onlinelibrary.wiley.com/journal/10.1111/(ISSN) 1445-5994/homepage/ForAuthors.html Version 12 FINAL1 $1^{\text {th }}$ November 2016 UK Spelling

20 Khan FA, Fisher MA, Khakoo RA. Association of hemochromatosis with infectious diseases: expanding spectrum. Int J Infect Dis. 2007; 11: 482-7.

21 Tefferi A, Pardanani A. Serious adverse events during ruxolitinib treatment discontinuation in patients with myelofibrosis. Mayo Clinic Proceedings. 201 1; 86: 1188-91.

Harrison CN, Talpaz M, Mead AJ. Ruxolitinib is effective in patients with intermediate-1 risk myelofibrosis: a summary of recent evidence. Leuk Lymphoma. 2016; 57: 2259-67.

23 Giraldo P, Palandri F, Palumbo GA, Zaritskey A, Calistri E, Skotnicki A, et al. P675 Safety and efficacy of ruxolitinib with intermediate-1-risk myelofibrosis from an open-label, multicenter, single-arm expanded access study. European Hematology Association. Vienna 2015. to ruxolitinib in patients with intermediate-1-, intermediate-2-, and high-risk myelofibrosis: results of the UK ROBUST Trial. Br J Haematol. 2015; 170: 29-39. Allogeneic hematopoietic cell transplantation for myelofibrosis in patients pretreated with the JAK1 and JAK2 inhibitor ruxolitinib. Bone Marrow Transplant. 2014; 49: 179-84.

26 Shanavas M, Popat U, Michaelis LC, Fauble V, McLornan D, Klisovic R, et al. Outcomes of Allogeneic Hematopoietic Cell Transplantation in Patients with Myelofibrosis with Prior Exposure to Janus Kinase $1 / 2$ Inhibitors. Biol Blood Marrow Transplant. 2016; 22: 432-40.

27 Zeiser R, Burchert A, Lengerke C, Verbeek M, Maas-Bauer K, Metzelder SK, et al. Ruxolitinib in corticosteroid-refractory graft-versus-host disease after allogeneic stem cell transplantation: a multicenter survey. Leukemia. 2015; 29: 2062-8. 
28 Robin M, Francois S, Huynh A, Cassinat B, Bay JO, Cornillon J, et al. Ruxolitinib before allogeneic hematopoietic stem cell transplantation (hsct) in patients with myelofibrosis: A preliminary descriptive report of the JAK ALLO Study, a Phase II trial sponsored by GoelamsFIM In collaboration with the Sfgmtc. Blood. 2013;

122.

29

Kroger N, Alchalby H, Ditschkowski M, Wolf D, Wulf G, Zabelina T, et al. Ruxolitnib as pretreatment before allogeneic stem cell transplantation for myelofibrosis. Blood. 2013; 122: 392.

Adir Y, Elia D, Harari S. Pulmonary hypertension in patients with chronic myeloproliferative disorders. Eur Respir Rev. 2015; 24: 400-10.

31 Tabarroki A, Lindner DJ, Visconte V, Zhang L, Rogers HJ, Parker Y, et al. Ruxolitinib leads to improvement of pulmonary hypertension in patients with myelofibrosis. Leukemia. 2014; 28: 1486-93.

32 Low AT, Howard L, Harrison C, Tulloh RM. Pulmonary arterial hypertension exacerbated by ruxolitinib. Haematologica. 2015; 100: e244-5.

33 Quintas-Cardama A, Kantarjian H, Pierce S, Cortes J, Verstovsek S. Prognostic model to identify patients with myelofibrosis at the highest risk of transformation to acute myeloid leukemia. Clin Lymphoma Myeloma Leuk. 2013; 13: 315-18 e2.

\section{ACKNOWLEDGEMENTS}

The authors thank Dr Belinda Butcher CMPP, WriteSource Medical Pty Ltd for medical writing assistance which was funded by an unrestricted educational grant from Novartis. 


\section{ABSTRACT [ 250 words]}

Ruxolitinib is a dual JAK1/ JAK2 inhibitor used to treat splenomegaly and/or symptoms associated with myelofibrosis (MF). Current therapeutic options for symptomatic myelofibrosis include supportive care, myelosuppressive therapy (such as hydroxycarbamide $(\mathrm{HC})$ ), and JAK inhibitors (in particular ruxolitinib). Allogeneic stem cell transplantation remains the only potentially curative treatment for MF, and younger transplant-eligible patients should still be considered for allogeneic stem cell transplantation, however this is applicable only to a small proportion of patients. There is now increasing and extensive experience of the efficacy and safety of ruxolitinib in myelofibrosis, both in clinical trials and "real world" practice. The drug has been shown to be of benefit in intermediate-1 risk patients with symptomatic splenomegaly or other MF-related symptoms, and higher risk disease. Optimal use of the drug is required to maximise clinical benefit, requiring an understanding of the balance between dose-dependent responses and dose-limiting toxicities. There is also increasing experience in the use of ruxolitinib in the pre-transplantation setting. This paper aims to utilise several "reallife" cases to illustrate a number of strategies which may help to optimise clinical practice.

KEYWORDS [5 MeSH]: ruxolitinib, primary myelofibrosis, janus kinases, prognosis, drug related side effects and adverse reactions

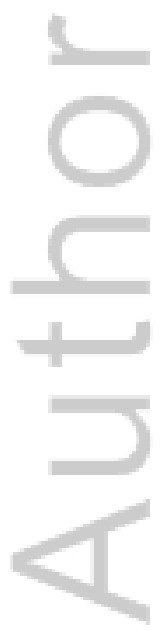

This article is protected by copyright. All rights reserved. 


\section{University Library}

\section{- M M I N E R VA \\ A gateway to Melbourne's research publications}

Minerva Access is the Institutional Repository of The University of Melbourne

Author/s:

Ho, PJ;Bajel, A;Burbury, K;Dunlop, L;Durrant, S;Forsyth, C;Perkins, AC;Ross, DM

Title:

A case-based discussion of clinical problems in the management of patients treated with ruxolitinib for myelofibrosis.

Date:

2017-03

Citation:

Ho, P. J., Bajel, A., Burbury, K., Dunlop, L., Durrant, S., Forsyth, C., Perkins, A. C. \& Ross, D. M. (2017). A case-based discussion of clinical problems in the management of patients treated with ruxolitinib for myelofibrosis.. Intern Med J, 47 (3), pp.262-268. https:// doi.org/10.1111/imj. 13341.

Persistent Link:

http://hdl.handle.net/11343/292558 